\title{
FOREWORD
}

For reprint orders, please contact: reprints@futuremedicine.com

\section{Message from the Editor}

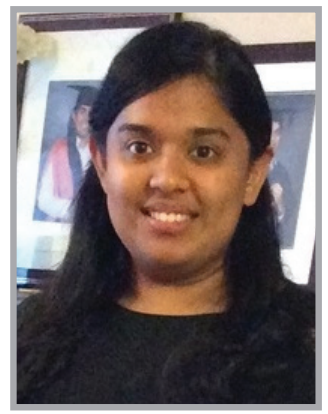

"We have covered a variety of subject areas including colorectal cancer screening, cost-effectiveness, biologic and molecular markers, KRAS mutation testing in colorectal cancer and surgical advances in colorectal cancer excision.”

\section{Roshaine A-M Wijayatunga*}

We have come to the end of 2016 and the end of volume 5 of Colorectal Cancer. In this final issue, as we close off this volume, we would like to take this opportunity to thank all our valued contributors - authors, reviewers, and editorial and production (both external and internal) teams for all their dedication, hard work and cooperation throughout this year. A big thank you also goes out to our illustrious Editorial Advisory Board Members, headed by Senior Editor Heinz-Josef Lenz, University of Southern California, USA and Associate Editors, Axel Grothey, Mayo Clinic, USA and John L Marshall, Georgetown University, USA, for all their input in this volume be it in an ambassadorial, advisory or authorship role - their time and efforts on behalf of Colorectal Cancer are very much appreciated and valued.

The content published in volume 5 of Colorectal Cancer has been of a very high standard, having gone through our rigorous peer-review and revisions process. We have covered a variety of subject areas including colorectal cancer screening, cost-effectiveness, biologic and molecular markers, KRAS mutation testing in colorectal cancer and surgical advances in colorectal cancer excision.

Article types have ranged from shorter opinion-based editorials and commentary pieces, to longer review-style articles and perspectives, alongside case reports, original research articles and interviews.

Many articles proved to be popular with our readers through this year and some of the most-read articles so far include:

- Editorial: Cardiac safety and toxicity minimization of regorafenib treatment (by Szucs and Jones) [1];

- Editorial: Allied therapies against BRAFmutated advanced colon cancer: the right plans to win the battle (by Kourie, Gharios and Kattan) [2];

- Interview: Why I became a cancer surgeon (by Poston) [3];

- Review: Biologic and molecular markers for staging colon carcinoma (by Bejarano, Garcia-Buitrago, Berho and Allende) [4];

- Management Perspective: Cost-effectiveness in colorectal cancer: challenges on quality and comparability (by Franken, van Rooijen, Uyl-de Groot, van Oijen and Koopman) [5];

- Special Report: Different modalities for colorectal cancer screening: experiences in The Netherlands so far (van Roon, van Dam, Spaander, Lansdorp-Vogelaar, Dekker and van Leerdam) [6].

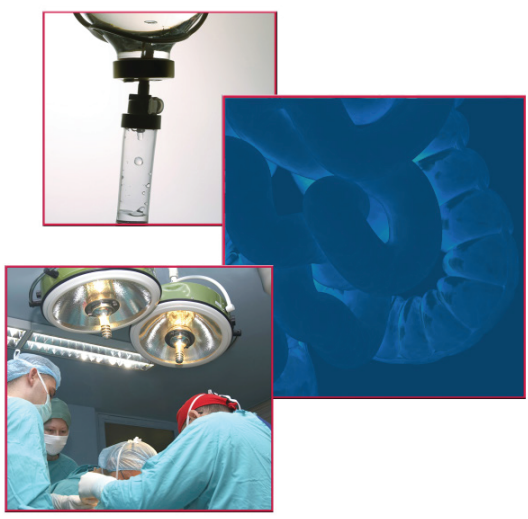

\section{KEYWORDS}

- Emerging Sources Citation Index

- highlights • Oncology Central

"We have many exciting plans for 2017 and beyond, some of which include making updates to our Aims and Scope, engaging a broader range of authors, reaching a wider audience and exploring new possibilities in terms of article types and coverage." 


\author{
“This new partnership \\ means that all members of \\ Oncology Central will \\ have full free access to \\ articles published in \\ Colorectal Cancer..."
}

Highlights in the last two issues of volume 5 include an editorial examining the role of tumor location within the colon as a predictive or prognostic factor in metastatic colon cancer [7], an original research article presenting analysis of patients with colorectal cancer and brain metastases [8] and a commentary discussing the management of $B R A F$-mutant metastatic colorectal cancer [9]. One article also looks at a surgical oncologist's perspective on liver surgery for metastatic colorectal cancers and authors discuss, "available evidence and indications for neoadjuvant treatment in the management of colorectal cancer liver metastases, on preoperative patient selection and identification of highrisk patients, potential treatment strategies to promote postoperative liver regeneration to avoid postoperative morbidity and potentially deleterious side effects of these therapies on tumor growth" [10].

\section{Emerging Sources Citation Index}

The end of 2015 saw Colorectal Cancer accepted onto Thomson's newest indexing service, Emerging Sources Citation Index. Emerging Sources Citation Index journals are included in Web of Science, and not only will this increase their discoverability, it will also aid in their subsequent assessments for SCIE. It can be considered a 'first stop' on the way to SCIE coverage and is also a definite marker of quality for our young journal.

\section{Social media}

Our editorial team have worked very hard to engage with the online community via twitter and we aim to continue to build on our success so far in reaching all stakeholders in the field of colorectal cancer research, from academics and clinicians to charities and patients. If you have not already done so, we would love to welcome you as a follower on Twitter (@fsgcrc).

\section{Oncology Central}

Toward the end of 2015 we announced that Colorectal Cancer, along with our other seven oncology management journal titles (Breast Cancer Management, CNS Oncology, Hepatic Oncology, International Journal of Endocrine Oncology, International Journal of Hematologic Oncology, Lung Cancer Management and Melanoma Management) had been partnered with Oncology Central [11].

Oncology Central is an online resource by Future Science Group and registration is free.
This resource is designed to meet the specific needs of our audience of medical professionals, aiming to deliver high-quality and relevant content in an accessible and innovative way all endorsed by an expanding board of expert Ambassadors. Through Oncology Central, we endeavor to keep our audience up to date with the latest developments in cancer research by providing unparalleled free access to the latest news, opinion, peer-reviewed journal articles, multimedia and exclusive content.

This new partnership means that all members of Oncology Central will have full free access to articles published in Colorectal Cancer and the other titles listed above.

If you would like to be a member of Oncology Central yourself, you will receive free access to timely news and expert opinion, along with all content published in Oncology Central-partnered journals. Please feel free to contact us via email: oncology.management@ futuremedicine.com.

\section{Conclusion}

We have many exciting plans for 2017 and beyond, some of which include making updates to our Aims and Scope, engaging a broader range of authors, reaching a wider audience and exploring new possibilities in terms of article types and coverage. We will be attending ECCO2017, The European Cancer Congress in Amsterdam in January 2017 - come and visit our stand if you are attending, if not, we hope to see you at other conferences we will be at during the coming year.

We welcome unsolicited article proposals and would be delighted to hear from you, particularly if you do have plans to submit original research articles and case reports, as we are looking to feature more of these specific article types in line with our scope as an oncology management journal.

We would love to hear from our readers regarding subject areas you would like to see featured in our journal and any other feedback you may have.

Thank you for your interest in our journal; we have achieved much this year and we look forward to bigger and better things for Colorectal Cancer in the New Year.

Financial \& competing interests disclosure

$R$ Wijayatunga is an employee of Future Medicine Ltd. The author has no other relevant affiliations or financial 
involvement with any organization or entity with a financial interest in or financial conflict with the subject matter or materials discussed in the manuscript. This includes employment, consultancies, honoraria, stock ownership or options, expert testimony, grants or patents received or pending, or royalties.

No writing assistance was utilized in the production of

this manuscript.

\section{References}

1 Szucs Z, Jones RL. Cardiac safety and toxicity minimization of regorafenib treatment. Colorect. Cancer 5(1), 1-3 (2016).

2 Kourie HR, Gharios J, Kattan J. Allied therapies against $B R A F$-mutated advanced colon cancer: the right plans to win the battle. Colorect. Cancer 5(2), 53-55 (2016).

3 Poston G. Why I became a cancer surgeon. Colorect. Cancer 5(1), 5-8 (2016).

4 Bejarano PA, Garcia-Buitrago MT, Berho M, Allende D. Biologic and molecular markers for staging colon carcinoma. Colorect. Cancer 5(1), 41-51 (2016).
5 Franken MD, van Rooijen EM, Uyl-de Groot CA, van Oijen MGH, Koopman M. Costeffectiveness in colorectal cancer: challenges on quality and comparability. Colorect. Cancer 5 (1), 21-31 (2016).

6 van Roon AHC, van Dam L, Spaander MC, Lansdorp-Vogelaar I, Dekker E, van Leerdam ME. Different modalities for colorectal cancer screening: experiences in The Netherlands so far. Colorect. Cancer 5(1), 9-19 (2016).

7 Kourie HR, Kattan J. Does tumor side represent a relevant factor for prognosis and treatment decision in metastatic colorectal cancer? Colorect. Cancer 5(3), 91-93 (2016).
8 Fukuda K, Matsuoka Y, Ota I, Seki H, Ito S, Kato S. Analysis of patients with colorectal cancer and brain metastases. Colorect. Cancer 5(3), 109-114 (2016).

9 Whitehall V, Burge M. Management of BRAF mutant metastatic colorectal cancer. Colorect. Cancer 5(4), 131-133 (2016).

10 Starlinger P, Assinger A, Brostjan C, Gruenberger T. Liver surgery for metastatic colorectal cancer - the surgical oncologist perspective. Colorect. Cancer 5(3), 115-125 (2016).

11 Oncology Central. www.oncology-central.com 